\title{
DESKRIPSI TEKNIS PENGENDALI TEMPERATUR INDUSTRI SEBAGAI BAGIAN DARI SISTEM REGULASI TEMPERATUR
}

\author{
Dista Yoel Tadeus, Iman Setiono \\ Program Studi DIII Teknik Elektro Departemen Teknologi Industri \\ Sekolah Vokasi Universitas Diponegoro Semarang \\ Jalan Prof. Sudharto, SH Tembalang Semarang \\ e-mail : distayoel@live.undip.ac.id
}

\begin{abstract}
Dista Yoel Tadeus, Iman Setiono, in this paper explain that temperature regulation is one of the most important needs for the industry. Lots of processes and production are carried out under certain temperature conditions and free from interference. Industrial temperature controller is one of the basic equipment to meet these needs. On the market there are various types, specifications, and brands of temperature controllers, but have similarities with one another mainly lies in the basic functions of temperature regulation capabilities. This article describes the background of industrial temperature controllers principal, also covers control concepts, basic controller configurations, control methods, actuator equipment support, and examples of sensor parameter settings and controls on the Autonics TC4S series temperature controllers.
\end{abstract}

Keywords: Temperature regulation, industrial temperature controller, ON-OFF control, PID

\section{PENDAHULUAN}

Pengendali temperatur adalah salah satu perangkat elektronik yang paling banyak digunakan di industri. Alat tersebut umumnya difungsikan sebagai regulator temperatur suatu proses baik proses pemanasan maupun pendinginan. Cara kerjanya yaitu dengan cara membandingkan sinyal dari sensor dengan sinyal referensi lalu melakukan perhitungan sesuai besar deviasi dari keduanya. Data hasil perhitungan tersebut kemudian digunakan untuk mengatur kerja peralatan pemanas atau pendingin.Pengendali temperatur industri dapat ditemukan dalam berbagai jenis dan karakteristik seperti berdimensi kompak dan modular, analog dan digital, satu saluran dan multi saluran, akurasi tinggi dan ekonomis, serta tipe general purpose yang cocok untuk banyak aplikasi. Selain itu terdapat juga pengendali temperatur yang memiliki fitur antarmuka komunikasi standar RS485 (protokol ModbusRTU) yang memungkinkan proses monitoring dan pengaturan alat dapat dilakukan melalui komputer.

Sensor yang didukung mulai dari tipe Resistive Temperature Device (RTD) seperti JPT 100, DPT 100, DPT 50, CU 100, CU 50, Nikel 120 dan tipe thermocouple seperti K, J, E, T, L, N, U, $\mathrm{R}, \mathrm{S}, \mathrm{B}, \mathrm{C}, \mathrm{G}$.

Metode kontrol yang ditanamkan pada pengendali temperatur industri umumnya meliputi ON-OFF, Proportional (P), Proportional-Integral (PI), Proportional-Derivative (PD), ProportionalIntegral-Derivative (PID). Tipe peralatan aktuasi yang didukung meliputi relay elektromekanis untuk mode ON-OFF dan solid state relay (SSR) untuk metodeON-OFF, P, PI, PD, dan PID.Bentuk sinyal aktuasi control outputdapat dipilih dalam tiga pilihan yaitu ON/OFF, Cycle, dan Phase. Ketiganya dapat digunakan pada SSR, untuk relay elektromekanis hanya dapat menggunakan pilihan ON/OFF.

Artikel ini memaparkan tentang cara kerja pengendali temperatur industri khususnya merk Autonics seri TC4S, termasuk pengaturansetelan parameter untuk sensor dan parameter metode kontrol untuk aplikasi regulasi temperatur pemanas elektrik.

\section{Prinsip Pengendali Temperatur}

Pengendali temperatur menggunakan skema sistem kendali umpan balik seperti yang ditunjukkan oleh Gambar 1.

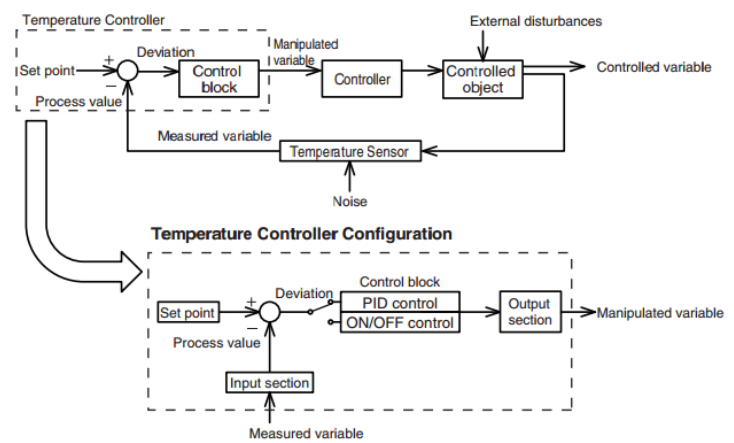

Gambar 1. Skema sistem kendali umpan balik

Pengendali temperatur membaca data dari sensor lalu membandingkan dengan set point atau referensi sehingga menghasilkan deviasi. Nilai deviasi digunakan sebagai salah satu variabel perhitungan tipe kontrol yang dipilih, ON/OFF atau PID. Sinyal kontrol yang dikeluarkan oleh blok kontrol akan mengatur kerja peralatan aktuasi, lalu peralatan aktuasi akan mengatur kerja peralatan pemanas atau pendingin. 


\section{Karakteristik Temperatur Objek}

Objek atau proses yang dikontrol terkait pengendalian temperatur umumnya memiliki karakteristik sebagai berikut:

- Kapasitas panas, mengindikasikan 'kemudahan' objek dalam menerima panas, bervariasi dengan ukuran ruang pemanas

- Karakteristik statik, mengindikasikan kemampuan pemanasan, bervariasi dengan kapasitas pemanas

- Karakteristik dinamik, mengindikasikan respon transien dari objek terhadap proses pemanasan, bervariasi dengan kapasitas pemanas dan ukuran ruang pemanas

- Gangguan eksternal berupa perubahan temperatur lingkungan

Pengendali temperatur mengontrol temperatur objek sehingga sama dengan nilai referensi atau set point. Namun respon objek dapat berbeda tergantung kepada karakteristik temperatur objek dan metode sistem kendali yang digunaan oleh pengendali temperature[1]. Secara umum, terdapat tiga macam respon seperti yang ditunjukkan oleh Gambar 2.

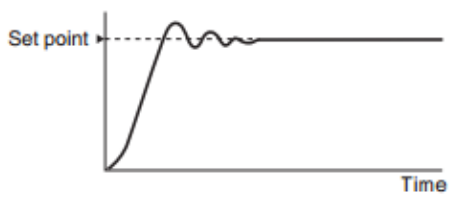

(a)

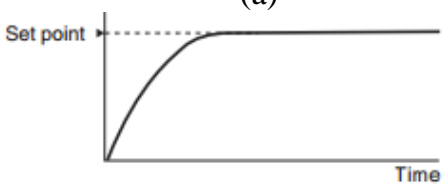

(b)

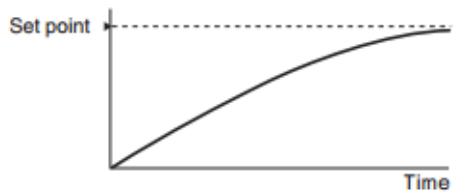

(c)

Gambar 2. Respon objek terhadap aksi pengendalian

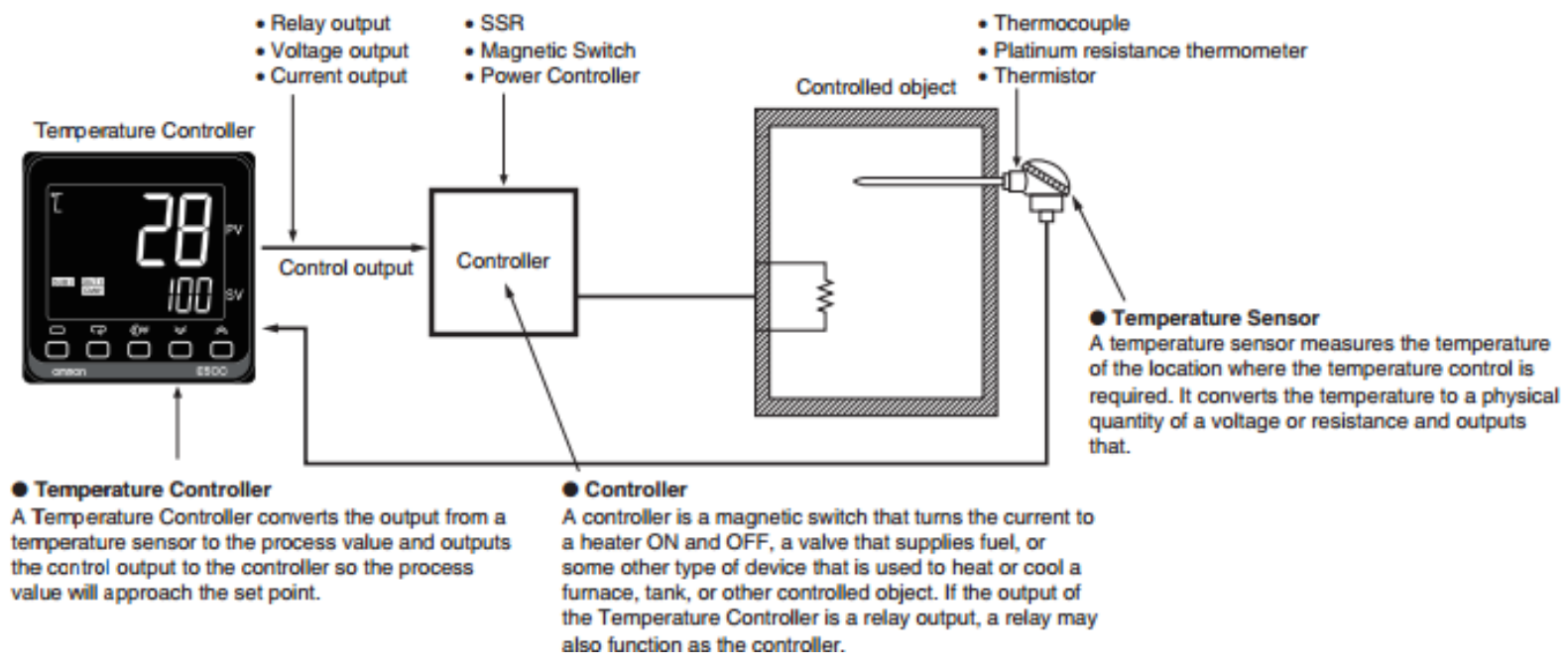

Gambar 3. Konfigurasi dasar sistem regulasi temperatur

Gambar 2 (a) menunjukkan respon objek yang mengalami overshooting dan undershooting sebelum akhirnya mencapai set point. Gambar 2 (b) menunjukkan respon objek yang bergerak mencapai set point dan tidak mengalami overshooting dan undershooting. Gambar 2 (c) menunjukkan respon objek yang lambat mencapai set point.

\section{Konfigurasi Pengendali Temperatur}

Secara umum konfigurasi sistem regulasi temperatur ditunjukkan oleh Gambar 3. Pengendali temperatur industri menerima data temperatur dari objek, membandingkan dengan referensi atau set point, mengeksekusi perhitungan metode kontrol, dan mengeluarkan sinyal perintah ke peralatan power kontroler yang terhubung langsung ke peralatan aktuator berupa elemen pemanas. Pengendali temperatur umumnya dapat menampilkan informasi nilai referensi atau set value (SV) dan process value (PV).

\section{Metode Kontrol}

Metode kontrol yang ditanamkan pada pengendali temperatur industri umumnya meliputi ON-OFF, Proportional (P), Proportional-Integral (PI), Proportional-Derivative (PD), ProportionalIntegral-Derivative (PID).Cara kerja metode kontrol ON-OFF ditunjukkan oleh Gambar 4. Jika PV lebih rendahdari SV, output akan aktif dan aliran dayadipasok ke pemanas. Jika PV lebih tinggi dariSV, output akan dimatikan dan aliran daya kepemanas akan putus. Respon objek cenderung berosilasi di sekitar nilai SV dan terdapat selisih antara SV dengan dengan PV yang disebut histerisis. Histerisis di dalam metode kontrol ON-OFF sangat penting karena berkaitan langsung dengan faktor 'kelelahan aktuator', 
umumnya histerisis dapat ditetapkan di dalam kontroler dan nilainya dipilih sesuai dengan karakteristik respon yang diinginkan.Metode kontrol ON-OFF dikenal juga sebagai aksi kontrol dua posisi.

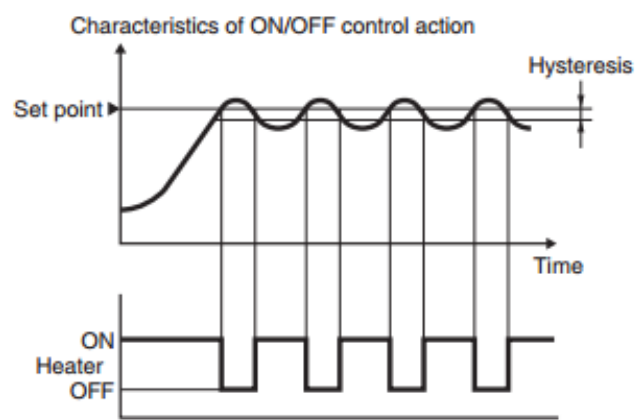

Gambar 4. Respon objek terhadap metode kontrol $\mathrm{ON}-\mathrm{OFF}$

Metode kontrol P, PI, PD, dan PID merupakan metode kontrol yang dapat terdiri dari satu atau lebih aksi kontrol sesuai dengan nama yang digunakannya. Aksi kontrol $\mathrm{P}$ digunakan untuk menghasilkanmanipulated variable (MV) yang sebanding dengan deviasierror untuk menurunkan penyimpanganantara SV dan PV. Merujuk ke Gambar 5, pita atau rentang proporsionaldiatur berada di tengah-tengahSV atau set point, dan MV ditentukandengan aturan berikut:

- MV dikeluarkan secara proporsional terhadap besar deviasi jika PV berada pada rentang pita proporsional

- $\quad$ MV sebesar $100 \%$ dikeluarkan jika PV lebih kecil dari batas bawah pita proporsional

- MV sebesar 0\% dikeluarkan jika PV lebih besar dari batas atas pita proporsional

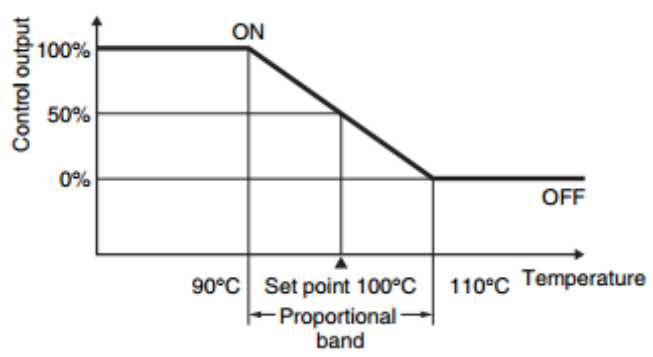

Gambar 5. Cara kerja aksi kontrol P

Metode kontrol dengan aksi kontrol $\mathrm{P}$ memiliki respon yang lebih baik daripada kontrol ON-OFF namun menimbulkan offset atau respon tidak mampu mencapai SV. Aksi kontrol I meningkatkan dan menurunkan nilai MV sesuai besar dan lama durasi deviasi. Offset yang muncul pada aksi kontrol $\mathrm{P}$ dapat hilang apabila dikombinasikan dengan aksi kontrol I sehingga menjadi PI seperti yang ditunjukkan oleh Gambar 6.

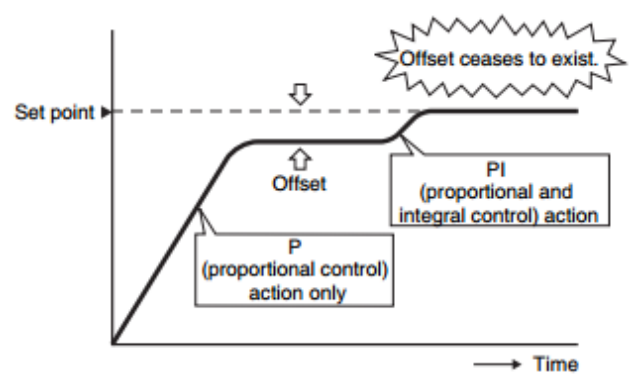

Gambar 6. Aksi kontrol PI dapat menghilangkan offset pada aksi kontrol $\mathrm{P}$

Aksi kontrol D akan mengeluarkan MV sebagai respon terhadap perubahan tiba-tiba pada PV yang dapat disebabkan oleh gangguan eksternal sehingga respon proses dapat diperbaiki seperti saat tanpa gangguan seperti yang ditunjukkan oleh Gambar 7.

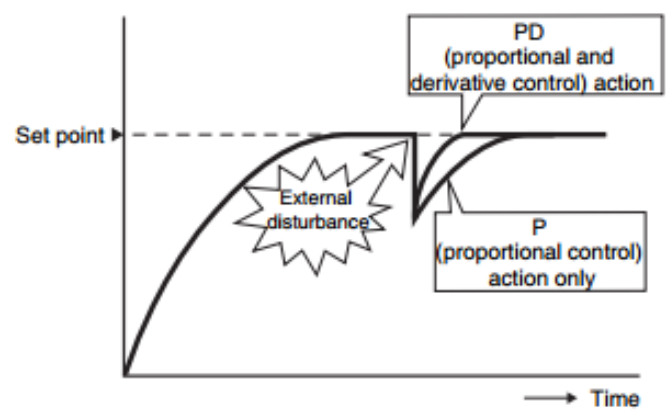

Gambar 7. Aksi kontrol D memperbaiki respon terhadap gangguan eksternal

Metode kontrol PID merupakan gabungan dari tiga aksi kontrol P, I, dan D. Temperatur dikontrol secarahalus dengan aksi kontrol proporsional, aksi integral akan menghilangkan offset,dan respons cepat terhadap gangguan eksternal ditangani olehaksi kontrol derivative. Gambar 8 menunjukkan cara kerja metode kontrol PID.

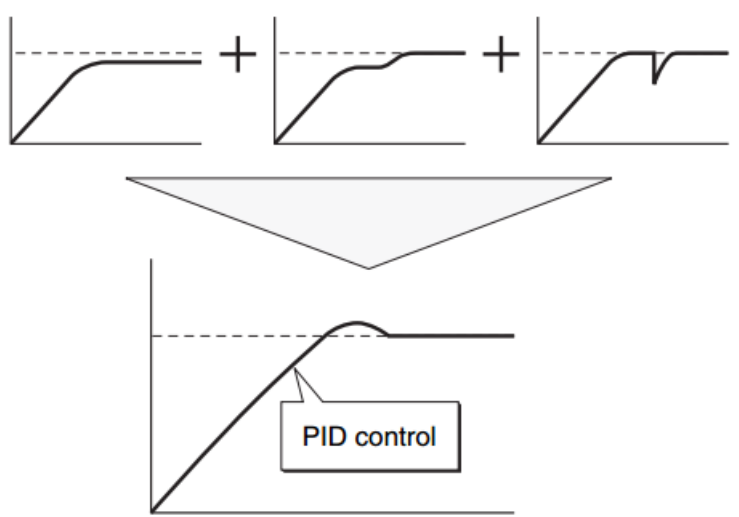

Gambar 8. Gabungan aksi kontrol P, I, dan D membentuk metode kontrol PID 


\section{Pengaturan Setelan Sensor Autonics TC4S}

Sesuai dengan Gambar 9, sensor thermocouple dihubungkan ke terminal 10 dan 11 . Mengacu ke Gambar 10 dengan menekan tombol Mode selama 4 detik maka akan muncul grup menu

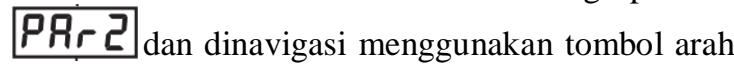
hingga muncul menu $\boldsymbol{n} \boldsymbol{-} \boldsymbol{L}$, di dalam menu ini dapat dipilih jenis sensor default yaitu 느 Selanjutnya adalah mengatur faktor koreksi pembacaan temperatur dengan cara menavigasi ke menu $\boldsymbol{i} \boldsymbol{n}$ dan memasukkan nilai yang sesuai dengan kalibrasi ${ }^{[2]}$.

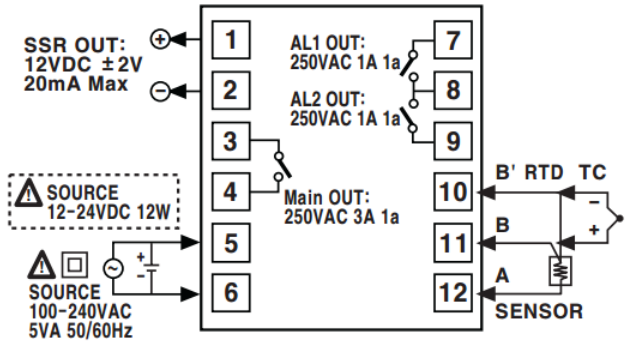

Gambar 9. Terminal Autonics TC4S

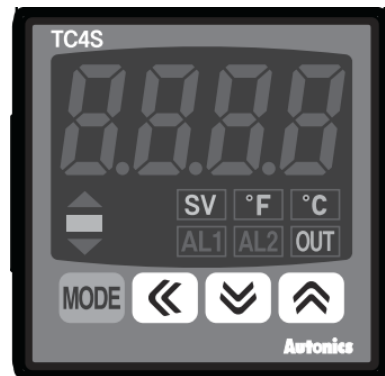

Gambar 10. Antarmuka Autonics TC4S

\section{Pengaturan Setelan Peralatan Aktuator Autonics TC4S}

Peralatan aktuator yang dapat digunakan adalah relay dan SSR. Terminal tegangan masukan SSR dihubungkan ke terminal 1 dan 2. Adapun SSR yang digunakan merek Fotek seri 25DA seperti yang ditunjukkan oleh Gambar $11^{[3]}$.

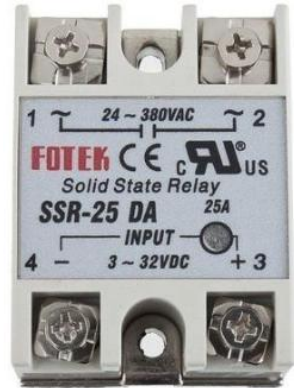

Gambar 11. SSR Fotek 25-DA

Mengacu ke Gambar 10 dengan menekan tombol Mode selama 4 detik maka akan muncul grup menu $P \boldsymbol{R}_{\boldsymbol{r}} \mathrm{C}$ dan dinavigasi menggunakan tombol arah hingga muncul menu a't untuk menentukan jenis peralatan aktuator, relay atau SSR. Saat dipilih SSR maka dapat dipilih jenis output SSR melalui menu $55 . \bar{n}$, pilihannya adalah Standard, Cycle, dan Phase. Setelah itu perlu menyetel waktu siklus kontrol dengan memilih menu secara default 20 detik untuk aktuator relay dan 2 detik untuk $\operatorname{SSR}^{[2]}$.

\section{Pengaturan Setelan Parameter PID Autonics TC4S}

Pengaturan parameter metode kontrol PID dilakukan dengan cara menekan Mode selama 2 detik maka akan muncul grup menu $\mathbf{P R \boldsymbol { r } \mathbf { ~ d a n }}$ dinavigasi menggunakan tombol arah hingga muncul menu $P$ untuk mengatur konstanta aksi proporsional, 1 untuk mengatur konstanta aksi integral, $\mathbf{d}$ untuk mengatur konstanta aksi derivative. Apabila menggunakan metode kontrol ON-OFF maka perlu diatur besar histerisis di menu 455 pada grup menu yang sama.

\section{Pengaturan Set Value (SV) atau Referensi Autonics TC4S}

Nilai SV dapat diatur dengan menekan sembarang tombol saat kontroler sedang berjalan. SV dapat diubah menjadi lebih besar atau lebih kecil dengan menekan tombol arah, dan untuk mengesetnya cukup dengan menekan tombol Mode $^{[2]}$.

\section{KESIMPULAN}

1. Pengendali temperatur industri mendukung dua jenis sensor temperatur yaitu RTD dan thermocouple.

2. Pengendali temperatur industri menggunakan konfigurasi sistem kendali umpan balik.

3. Pengendali temperatur industri memiliki dua metode kontrol yaitu ON-OFF dan PID.

4. Pengendali temperatur industri menyediakan akses pengaturan parameter kontrol PID yaitu konstanta aksi proporsional, integral, dan derivative.

5. Pengendali temperatur industri menyediakan akses pengaturan parameter kontrol ON-OFF yaitu pengaturan histerisis.

6. Pengendali temperatur industri mendukung dua jenis peralatan aktuator yaitu relay dan SSR.

7. Pengendali temperatur industri menyediakan akses pengaturan waktu siklus kontrol sesuai dengan peralatan aktuator yang dipilih. 
DAFTAR PUSTAKA

1. Omron, 2018, Technical Explanation for Temperature Controllers. Omron Corporation.

2. Autonics, 2018, Temperature Controller TC4 Series Manual. Autonics Corporation.

3. Fotek, 2018, Fotek Solid State Module Datasheet. Fotek Controls LTD. 